\title{
Compound-specific isotope analysis of benzotriazole and its derivatives
}

\author{
Stephanie Spahr · Sebastian Huntscha • Jakov Bolotin • \\ Michael P. Maier • Martin Elsner · Juliane Hollender • \\ Thomas B. Hofstetter
}

Received: 17 September 2012 / Revised: 19 October 2012 / Accepted: 24 October 2012 / Published online: 9 December 2012

(c) Springer-Verlag Berlin Heidelberg 2012

\begin{abstract}
Compound-specific isotope analysis (CSIA) is an important tool for the identification of contaminant sources and transformation pathways, but it is rarely applied to emerging aquatic micropollutants owing to a series of instrumental challenges. Using four different benzotriazole corrosion inhibitors and its derivatives as examples, we obtained evidence that formation of organometallic complexes of benzotriazoles with parts of the instrumentation impedes isotope analysis. Therefore, we propose two strategies for accurate $\delta^{13} \mathrm{C}$ and $\delta^{15} \mathrm{~N}$ measurements of polar organic micropollutants by gas chromatography isotope ratio mass spectrometry (GC/IRMS). Our first approach avoids metallic components and uses a $\mathrm{Ni} / \mathrm{Pt}$ reactor for benzotriazole combustion while the second is based on the coupling of online methylation to the established GC/IRMS setup. Method detection limits for on-column injection of benzotriazole, as well as its $1-\mathrm{CH}_{3}-, 4-\mathrm{CH}_{3}-$, and 5$\mathrm{CH}_{3}$-substituted species were $0.1-0.3 \mathrm{mM}$ and $0.1-1.0 \mathrm{mM}$ for $\delta^{13} \mathrm{C}$ and $\delta^{15} \mathrm{~N}$ analysis respectively, corresponding to injected masses of $0.7-1.8 \mathrm{nmol} \mathrm{C}$ and $0.4-3.0 \mathrm{nmol} \mathrm{N}$,
\end{abstract}

Published in the topical collection Isotope Ratio Measurements: New Developments and Applications with guest editors Klaus G. Heumann and Torsten C. Schmidt.

Electronic supplementary material The online version of this article (doi:10.1007/s00216-012-6526-1) contains supplementary material, which is available to authorized users.

S. Spahr · S. Huntscha $\cdot$ J. Bolotin · J. Hollender .

T. B. Hofstetter $(\square)$

Environmental Chemistry, EAWAG, Überlandstrasse 133, 8600 Dübendorf, Switzerland

e-mail: Thomas.Hofstetter@eawag.ch

M. P. Maier - M. Elsner

Institute of Groundwater Ecology, Helmholtz Zentrum München, Ingolstädter Landstr. 1, 85764 Neuherberg, Germany respectively. The $\mathrm{Ni} / \mathrm{Pt}$ reactor showed good precision and was very long-lived (>1000 successful measurements). Coupling isotopic analysis to offline solid-phase extraction enabled benzotriazole-CSIA in tap water, wastewater treatment effluent, activated sludge, and in commercial dishwashing products. A comparison of $\delta^{13} \mathrm{C}$ and $\delta^{15} \mathrm{~N}$ values from different benzotriazoles and benzotriazole derivatives, both from commercial standards and in dishwashing detergents, reveals the potential application of the proposed method for source apportionment.

Keywords CSIA - Gas chromatography isotope ratio mass spectrometry $\cdot$ Benzotriazole $\cdot$ Corrosion inhibitors .

Micropollutants $\cdot$ Source identification

\section{Introduction}

The increasing contamination of water resources with organic micropollutants is a major environmental problem $[1,2]$. Many of the synthetic chemicals that are currently introduced into the aquatic environment through human activity are relatively polar and therefore quite mobile [2]. Assessing the exposure of humans and the environment to aquatic micropollutants is challenging, however, because knowledge of degradation is often elusive and estimates on the amount of degraded contaminant can barely be obtained. Moreover, the widespread use of anthropogenic chemicals also leads to multiple contamination sources that are difficult to distinguish. It has therefore been proposed to use compound-specific isotope analysis (CSIA) to assess micropollutant degradation processes in individual micropollutants [3, 4].

As has been shown for traditional organic contaminants such as chlorinated solvents, fuel additives, and explosives, 
CSIA is ideally suited to contribute to the fate assessment [3-7]. Conservative isotope signatures enable source apportionment while changing isotope signatures provide robust evidence for (bio)degradation and its pathways. However, to carry out CSIA using the typical instrumentation (i.e., gas chromatography coupled to isotope ratio mass spectrometry, GC/IRMS), a series of challenges have to be addressed. (a) GC/IRMS systems exhibit rather poor sensitivity requiring extensive sample enrichment, which can, in principle, lead to isotope fractionation artifacts $[5,6,8]$. (b) Many contaminants contain polar functional groups (alcohol, amino, or carboxyl groups, $\mathrm{N}$-heteroatoms) that reduce their volatility and thermal stability thus compromising their analysis by GC/IRMS. (c) Some compounds are suspected to be converted incompletely to analyte gases (i.e., $\mathrm{CO}_{2}$ and $\mathrm{N}_{2}$ ) leading to high detection limits and inaccurate isotope ratio measurements [9]. (d) Finally, several micropollutants have the potential to form organometallic complexes that may hinder isotopic analysis due to the presence of metals (e.g., stainless steel, $\mathrm{Cu}, \mathrm{Ni}, \mathrm{Pt}$ ) in commercial GC/IRMS systems.

In this study, we present an approach for CSIA of benzotriazoles, representing an important class of emerging micropollutants. Because benzotriazoles are mobile and persistent, they are widely found in rivers, lakes, and groundwater in the nanograms per liter up to the low micrograms per liter range [10-15]. 1H-benzotriazole (1H-BT) and its methylated derivatives 4-methyl-benzotriazole $\left(4-\mathrm{CH}_{3}-\mathrm{BT}\right)$ and 5-methyl-benzotriazole (5- $\mathrm{CH}_{3}-\mathrm{BT}$, which is often used in technical tolyltriazole mixtures including $4-\mathrm{CH}_{3}-\mathrm{BT}$ ) are high production volume chemicals with a worldwide annual production in the range of 9000 tons/year [16]. They are widely used as corrosion inhibitors in aircraft deicing and anti-icing fluids, cooling liquids, and brake fluids as well as for silver protection in dishwashing detergents [17, 18]. Benzotriazole and its derivatives also play an important role as synthetic auxiliaries in organic chemistry [19] and are used for UV stabilization in plastics [20].

Knowledge of the processes governing benzotriazole transport and transformation in aquatic environments is, despite recent advances, scarce [21, 22]. CSIA can offer additional insight into mechanisms of transformation processes and could enable one to identify contaminant sources. It was therefore the goal of this study to provide methods for accurate, that is true and precise $\mathrm{C}$ and $\mathrm{N}$ isotope analysis of benzotriazoles by CSIA and to apply one of them for environmental analysis and supplier identification of benzotriazoles in dishwashing detergents. However, isotopic analysis of benzotriazoles by conventional GC/IRMS is challenging, because benzotriazoles are not only very polar but also exhibit low vapor pressures [13] and tend to form complexes at metal surfaces (e.g., with $\mathrm{Cu}$ alloys, [23, 24]), so that interactions of benzotriazoles with metal-containing parts present in GC/IRMS systems can compromise isotopic analysis. We therefore evaluated two complementary approaches including (a) the replacement of metal parts in a typical GC/IRMS system (modified standard setup) and (b) the derivatization of benzotriazoles to less polar and more volatile products which do not form strong metal complexes (online derivatization). The modified standard setup was further investigated for CSIA of $1 \mathrm{H}-\mathrm{BT}$ and three methylated benzotriazole species $\left(1-\mathrm{CH}_{3}-/ 4-\mathrm{CH}_{3}-/ 5\right.$ $\mathrm{CH}_{3}$-BT) in environmental matrices and in dishwashing detergents. To this end, we tested the benzotriazole enrichment by solid-phase extraction (SPE) and its coupling to isotopic analysis in tap water, wastewater treatment plant effluent, and in activated sludge as well as in commercial dishwashing products.

\section{Experimental section}

A complete list of all used chemicals including abbreviations, purities, and suppliers, as well as a description of the sampling procedure at the wastewater treatment plant, is provided in the Electronic Supplementary Material (Table S1).

\section{Solid-phase extraction}

The performance of three commercially available SPE cartridges containing the three following adsorbent materials was compared with regard to purification and enrichment of benzotriazoles: (1) Oasis HLB $\left(6 \mathrm{~cm}^{3}\right.$ cartridges, $200 \mathrm{mg}$; Waters, Milford, MA, USA), a reversed-phase sorbent, was used to retain neutral benzotriazole species (sample $\mathrm{pH}$ 2.0); (2) ENVI-Carb (Supelclean ENVI-Carb SPE tubes $6 \mathrm{~cm}^{3}, 250$ and $500 \mathrm{mg}$; Supelco; Bellefonte, PA, USA), a graphitized carbon material, was tested as an alternative sorbent for neutral benzotriazole species (sample $\mathrm{pH} 2.0$ ); and (3) Oasis MAX $\left(6 \mathrm{~cm}^{3}\right.$ cartridges, $150 \mathrm{mg}$; Waters, MA, USA), a mixed-mode anion exchange sorbent, was used to retain anionic benzotriazole species (sample $\mathrm{pH}$ 10.6). All SPE materials were evaluated with three different matrices, namely, tap water, wastewater treatment plant effluent, and activated sludge.

Depending on the used SPE sorbent, the $\mathrm{pH}$ of 100$\mathrm{mL}$ sample was adjusted to $2.0 \pm 0.1$ with $1 \mathrm{M} \mathrm{HCl}$ or to $10.6 \pm 0.1$ with $5 \% \mathrm{NH}_{4} \mathrm{OH}$. Samples were then spiked with benzotriazoles to obtain final concentrations of 0.5 , 1.5 , or $2.5 \mu \mathrm{M} 1-\mathrm{CH}_{3}-\mathrm{BT}$ and 1,3 , or $5 \mu \mathrm{M} 1 \mathrm{H}-\mathrm{BT}$, 4$\mathrm{CH}_{3}-\mathrm{BT}$, and $5-\mathrm{CH}_{3}-\mathrm{BT}$, respectively. A blank was run 
under identical conditions except for the addition of benzotriazoles. All samples were filtered with $0.7 \mu \mathrm{m} \mathrm{GF-F}$ filters (glass microfiber filters, Whatman, $47 \mathrm{~mm}$ ) after the addition of benzotriazoles and percolated through the conditioned cartridges with a flow rate of approximately $1 \mathrm{~mL} / \mathrm{min}$. Subsequently, the cartridges were washed with 4-5 mL water, dried for at least $1 \mathrm{~h}$ at room temperature and benzotriazoles were eluted with $10 \mathrm{~mL}$ of different organic solvents. Detailed SPE protocols are provided in Table S2. For GC/MS analysis, extracts were evaporated at $30{ }^{\circ} \mathrm{C}$ under a gentle stream of $\mathrm{N}_{2}$ to $1 \mathrm{~mL}$ and further diluted with ethyl acetate to obtain benzotriazole concentrations within the calibrated range of the instrument (8-40 $\mu \mathrm{M})$. GC/IRMS analysis required further solvent evaporation to achieve a final volume of $100 \mu \mathrm{L}$.

Domestic dishwashing detergents

Domestic dishwashing powders and tabs from 12 commercial products were crushed with a pestle, and varying amounts (10-100 mg) were dissolved in $100 \mathrm{~mL}$ nanopure water. Dissolution was achieved after $15 \mathrm{~min}$ of sonication. Subsequently, the $\mathrm{pH}$ of each sample was adjusted to $2.0 \pm 0.1$ with $1 \mathrm{M} \mathrm{HCl}$, and samples were enriched by SPE using Oasis HLB cartridges. For GC/MS and GC/IRMS analysis, sample extracts were evaporated under a gentle flow of $\mathrm{N}_{2}$ to $1 \mathrm{~mL}$ and $100 \mu \mathrm{L}$, respectively.

\section{GC/MS analysis}

Modified standard setup Concentration analysis of benzotriazoles was conducted with a GC/MS system (TRACE GC Ultra/TRACE DSQ EI 250, Thermo). Liquid samples $(1 \mu \mathrm{L}$ in ethyl acetate) were injected with a Combi PAL autosampler (CTC Analytics) in a split/splitless injector operated for $1 \mathrm{~min}$ in splitless and then in split mode with a split flow of $50 \mathrm{~mL} / \mathrm{min}$ at a temperature of $200{ }^{\circ} \mathrm{C}$. Helium was used as carrier gas at constant pressure $(100 \mathrm{kPa})$. The GC was equipped with $1 \mathrm{~m}$ of an OV-1701-OH deactivated fused-silica guard column $(660 \mu \mathrm{m}$ OD, $530 \mu \mathrm{m}$ ID, BGB Analytik), a $30 \mathrm{~m} \times 0.32 \mathrm{~mm}$ RTX-5 Amine column (Crossbond $5 \%$ diphenyl/95 \% dimethyl polysiloxane, $1 \mu \mathrm{m} \mathrm{df}$, Restek), and $0.4 \mathrm{~m} \mathrm{OV-1701-OH}$ deactivated fused-silica postcolumn (450 $\mu \mathrm{m}$ OD, $180 \mu \mathrm{m}$ ID, BGB Analytik). Universal PressFit Connectors ( 0.3 to $0.75 \mathrm{~mm}$ OD, deactivated, BGB Analytik) and a Universal PressFit 4-way X-splitter ( 0.2 to $0.75 \mathrm{~mm}$ OD, deactivated, BGB Analytik) were used. The temperature program used to obtain baselineseparated analyte peaks was $1 \mathrm{~min}$ at $80{ }^{\circ} \mathrm{C}, 15^{\circ} \mathrm{C} / \mathrm{min}$ to $180{ }^{\circ} \mathrm{C}(10 \mathrm{~min})$, and $40{ }^{\circ} \mathrm{C} / \mathrm{min}$ to $250{ }^{\circ} \mathrm{C}(5 \mathrm{~min})$. Benzotriazoles were quantified with external calibration using seven standard mixtures containing the four benzotriazole species in concentrations ranging from 8 to $40 \mu \mathrm{M}$. The mass spectrometer was operated in the full scan mode $(\mathrm{m} / \mathrm{z}, 50-400)$.

Online derivatization of benzotriazoles Benzotriazole online derivatization by trimethylsulfonium hydroxide (TMSH) was carried out using the same GC/MS instrument, setup, and injector (at $230^{\circ} \mathrm{C}$ ) described above. Each single benzotriazole standard ( $1 \mathrm{mM}$ in ethyl acetate) was mixed with TMSH in 50-fold excess ( $25 \mathrm{mM}$ ethyl acetate) to obtain analyte concentrations of $40 \mu \mathrm{M}$. Benzotriazole derivatives were identified based on GC/MS retention times and mass spectra. Tentative derivatization efficiencies were estimated from the lowest detectable concentration of underivatized benzotriazole $\left(c_{\mathrm{min}}^{\mathrm{BT}}\right)$, and the theoretical concentration of benzotriazole injected with TMSH $\left(c_{\text {theoretical,TMSH }}^{\mathrm{BT}}\right)$, as follows:

Derivatization efficiency $=\left(1-\frac{c_{\min }^{\mathrm{BT}}}{c_{\text {theoretical,TMSH }}^{\mathrm{BT}}}\right) \cdot 100 \%$

\section{GC/IRMS analysis}

Modified standard setup Analysis of $\delta^{13} \mathrm{C}$ and $\delta^{15} \mathrm{~N}$ values of pure chemicals was carried out using a TRACE GC coupled to an isotope ratio mass spectrometer via a $\mathrm{GC}$ Combustion III interface (GC/IRMS 1, Thermo). C and $\mathrm{N}$ isotope analysis were almost identical, except for cryogenic trapping of $\mathrm{CO}_{2}$ in liquid $\mathrm{N}_{2}$ during $\delta^{15} \mathrm{~N}$ measurements. The GC setup and the temperature program were identical to GC/MS analysis described in Section "Modified standard setup" except for the larger postcolumn inner diameter $(320 \mu \mathrm{m})$. The self-made oxidation reactor consisted of a ceramic tube $(1.5 \mathrm{~mm}$ OD, $0.55 \mathrm{~mm}$ ID, $32 \mathrm{~cm}$ length, Thermo) containing two nickel wires (diameter $0.1 \mathrm{~mm}$, length $30 \mathrm{~cm}$, purity $99.99 \%$, Alfa Aesar) and one platinum wire (diameter $0.1 \mathrm{~mm}$, length $30 \mathrm{~cm}$, purity $99.99 \%$, Goodfellow). The same $\mathrm{Ni} / \mathrm{Ni} / \mathrm{Pt}$ reactor (referred to as $\mathrm{Ni}$ reactor in the succeeding text) operated at $1000^{\circ} \mathrm{C}$ was used for $\mathrm{C}$ and $\mathrm{N}$ isotope analysis. One $\mathrm{Ni}$ reactor was used throughout the study covering approximately 1200 measurements. After every measurement, the reactor was reoxidized for 20 min with a continuous $\mathrm{O}_{2}$ stream at $1000{ }^{\circ} \mathrm{C}$ after optimum reoxidation times had been evaluated between 1 and $30 \mathrm{~min}$ (data not shown). For reduction of nitrogen oxides, a standard reduction reactor (Thermo) containing three wires of copper was operated at $650{ }^{\circ} \mathrm{C}$. 
$\mathrm{C}$ and $\mathrm{N}$ isotope ratios are expressed in the delta notation as $\delta^{13} \mathrm{C}$ and $\delta^{15} \mathrm{~N}$, respectively, (Eq. 2), in which the concentrations of heavy $\left({ }^{h} E\right)$ and light $\left({ }^{l} E\right)$ isotopologs of $\mathrm{C}$ and $\mathrm{N}$ (designated as element $E$ ) are reported relative to Vienna Pee Dee Belemnite and air, respectively.

$\delta^{h} E[\% 0]=\frac{\left({ }^{h} E /{ }^{l} E\right)_{\text {sample }}}{\left({ }^{h} E /{ }^{l} E\right)_{\text {standard }}}-1$

To evaluate the trueness and precision of isotope measurements, the $\mathrm{C}$ and $\mathrm{N}$ isotope composition of four benzotriazole standards (1H-BT, 1- $\mathrm{CH}_{3}-, 4-\mathrm{CH}_{3}-, 5-\mathrm{CH}_{3}-\mathrm{BT}$ ) was measured by an elemental analyzer (EA, Carlo Erba) coupled to an IRMS (EA/IRMS, Fisons Optima, Table S4). Trueness of isotope signatures, $\Delta \delta^{h} E$, is reported as deviation of the isotope ratio measurements by GC/IRMS $\left(\delta^{h} E_{\mathrm{GC} / \mathrm{IRMS}}\right)$ from the reference isotope signatures of four in-house working standards $\left(\delta^{h} E_{\text {ref }}\right.$, Eq. 3 ). If not specified otherwise, isotope signatures are reported as arithmetic mean of triplicate measurements with 1 standard deviation $( \pm \sigma)$ as measure for instrumental precision.

$\Delta \delta^{h} E=\delta^{h} E_{\mathrm{GC} / \mathrm{IRMS}}-\delta^{h} E_{\mathrm{ref}}$

Online derivatization approach For the online derivatization approach, a different GC/IRMS instrumentation (GC/ IRMS 2) was used that is described in detail in Reinnicke et al. [25]. Online derivatization of benzotriazole with TMSH was carried out using a programmable temperature vaporizer (PTV) injector (Optic 3-SC High Power Injection System, ATAS GL International B.V.) equipped with a large-volume glassbead liner (PAS Technology). Between 1 and $100 \mu \mathrm{L}$ of a premixed solution with $0.8 \mathrm{mM} 1 \mathrm{H}$ BT (Fluka) and TMSH (250-fold excess) in methanol was injected via a GC Pal autosampler into the glassbead liner at $40{ }^{\circ} \mathrm{C}$. Depending on the injected sample volume, a vent time between $30 \mathrm{~s}$ (for $1 \mu \mathrm{L}$ ) and $630 \mathrm{~s}$ (for $100 \mu \mathrm{L}$ ) was used with a split flow of $50 \mathrm{~mL} / \mathrm{min}$ to remove the solvent (methanol). Subsequently, the split flow was set to $0 \mathrm{~mL} / \mathrm{min}$ for $60 \mathrm{~s}$ (column flow $1.4 \mathrm{~mL} / \mathrm{min}$ ) and the injector was heated with a rate of $7{ }^{\circ} \mathrm{C} / \mathrm{s}$ to $300{ }^{\circ} \mathrm{C}$. The GC setup and the temperature program were identical to the GC/MS analysis described in Section "Modified standard setup." A commercially available $\mathrm{Ni}$ tube/NiO-CuO combustion reactor with a silcosteel capillary (Thermo) operated at $1000{ }^{\circ} \mathrm{C}$ was used for $\delta^{13} \mathrm{C}$ and $\delta^{15} \mathrm{~N}$ analysis and was reoxidized after approximately 40 injections. For reduction of nitrogen oxides, a standard reduction reactor (Thermo) was operated for $\mathrm{N}$ isotope measurements at $640{ }^{\circ} \mathrm{C}$. Isotope signatures for $1 \mathrm{H}-\mathrm{BT}$ were calculated as follows using the isotope values of the derivatives $\left(1-\mathrm{CH}_{3}-\mathrm{BT}\right.$ and $2-\mathrm{CH}_{3}-$ BT) and the corresponding peak areas of mass 28 or 44
( $A^{28}$ and $A^{44}$ ), respectively. The calculation of $\delta^{13} \mathrm{C}$ values for 1H-BT further required correction for the introduced carbon atom through methylation $\left(\delta^{13} \mathrm{C}_{\mathrm{EA}, \mathrm{TMSH}}\right)$.

$$
\begin{aligned}
& \delta^{15} \mathrm{~N}_{1 \mathrm{HBT}}[\% 0] \\
& =\frac{\delta^{15} \mathrm{~N}_{1 \mathrm{CH}_{3} \mathrm{BT}} \cdot A_{1 \mathrm{CH}_{3} \mathrm{BT}}^{28}+\delta^{15} \mathrm{~N}_{2 \mathrm{CH}_{3} \mathrm{BT}} \cdot A_{2 \mathrm{CH}_{3} \mathrm{BT}}^{28}}{A_{1 \mathrm{CH}_{3} \mathrm{BT}}^{28}+A_{2 \mathrm{CH}_{3} \mathrm{BT}}^{28}}
\end{aligned}
$$

$$
\begin{aligned}
\delta^{13} \mathrm{C}_{1 \mathrm{HBT}}[\% 0] \\
=\frac{7}{6} \cdot\left(\frac{\delta^{13} \mathrm{C}_{1 \mathrm{CH}_{3} \mathrm{BT}} \cdot A_{1 \mathrm{CH}_{3} \mathrm{BT}}^{44}+\delta^{13} \mathrm{C}_{2 \mathrm{CH}_{3} \mathrm{BT}} \cdot A_{2 \mathrm{CH}_{3} \mathrm{BT}}^{44}}{A_{1 \mathrm{CH}_{3} \mathrm{BT}}^{44}+A_{2 \mathrm{CH}_{3} \mathrm{BT}}^{44}}\right) \\
\quad-\frac{1}{6} \cdot \delta^{13} \mathrm{C}_{\mathrm{EA}, \mathrm{TMSH}}
\end{aligned}
$$

Online derivatization approach vs. modified standard setup For method comparison, the online derivatization approach and the modified standard setup were implemented consecutively on the same GC/IRMS instrument. Therefore, GC/IRMS 2 that was used for the online derivatization approach was equipped with the same guard, chromatographic, and postcolumn as well as with the same self-made oxidation reactor than used in the modified standard setup. Between 1 and $100 \mu \mathrm{L}$ benzotriazole standard compound in ethyl acetate (without TMSH) was then injected onto the GC column via the PTV injector which was heated with a rate of $5^{\circ} \mathrm{C} / \mathrm{s}$ to $230^{\circ} \mathrm{C}$.

Method detection limits Instrument linearity and method detection limits (MDLs) were determined from isotope ratio measurements of four benzotriazole working standards at different concentrations following the moving mean procedure proposed by Jochmann et al. [26]. Injected concentration ranges were $0.025-1 \mathrm{mM}$ and $0.125-5 \mathrm{mM}$ for $\delta^{13} \mathrm{C}$ and $\delta^{15} \mathrm{~N}$ analysis, respectively. MDLs were determined using two different uncertainty intervals: (a) constant $\delta^{13} \mathrm{C}$ and $\delta^{15} \mathrm{~N}$ intervals of \pm 0.5 and $\pm 1 \%$, respectively (referred to as MDL), and (b) variable intervals covering $\pm 2 \sigma$ of all data points used for the calculation of the moving mean $\left(\mathrm{MDL}_{2 \sigma}\right)$.

\section{Results and discussion}

Analytical strategies for CSIA of benzotriazoles by GC/IRMS

Isotopic analyses of $1 \mathrm{H}-, \quad 4-\mathrm{CH}_{3}^{-}$, and $5-\mathrm{CH}_{3}-$ benzotriazoles by standard GC/IRMS systems via on-column injection did not lead to detectable peaks even 
at high analyte concentrations (up to $15 \mathrm{mmol} / \mathrm{L}$ ) while that of $1-\mathrm{CH}_{3}$-benzotriazole was feasible (Fig. 1a). Because the ability of benzotriazoles to form organometallic complexes requires nitrogen lone pair electrons [23, 24], our observation suggests that interactions of $1 \mathrm{H}-, 4-\mathrm{CH}_{3-}^{-}$, and 5- $\mathrm{CH}_{3}$-benzotriazoles with metal parts of the GC/IRMS system, in particular with $\mathrm{Cu}$ in the $\mathrm{Cu} / \mathrm{Ni} / \mathrm{Pt}$-containing oxidation reactor, impede isotopic analysis. As shown in Fig. 1b, replacing stainless steel-containing parts by silicate-based ones (PressFit Connectors, PressFit XSplitter, Section "Modified standard setup") and removing $\mathrm{Cu}$ wires from the oxidation reactor enabled us to carry out
CSIA of all four benzotriazole species. This approach is henceforth referred to as the modified standard setup which was, unless otherwise specified, implemented on GC/IRMS 1. Alternatively, as implied by the isotopic analyses of 1- $\mathrm{CH}_{3}$-benzotriazole, $\mathrm{N}$-methylation on the triazole ring reduces interactions of the molecule with metal surfaces [24] and thus allows one to use $\mathrm{Cu}$-containing, standard GC/IRMS systems for benzotriazole-CSIA. An example of such a derivatization using TMSH is shown in Fig. 1c-g and the isotope analysis of derivatized benzotriazoles is discussed in Section "Benzotriazole-CSIA using online derivatization".

\section{GC/IRMS}

a)
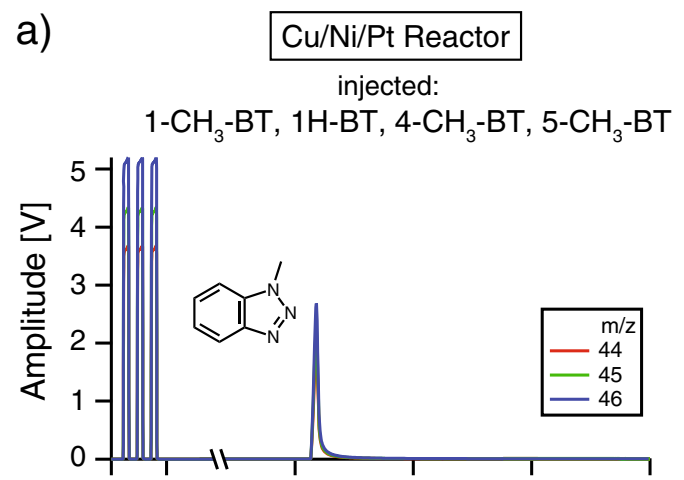

b)

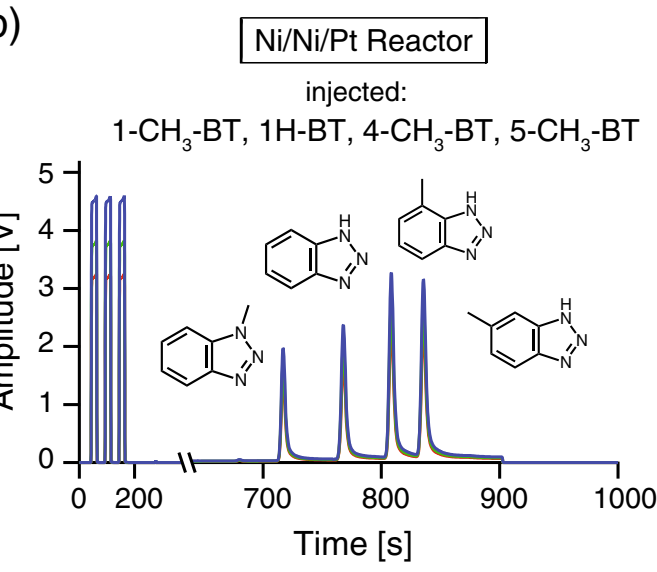

Fig. 1 GC/IRMS chromatograms (left): a $1-\mathrm{CH}_{3}-\mathrm{BT}$ was the only compound detected from a mixture of $1 \mathrm{H}-\mathrm{BT}, 1-\mathrm{CH}_{3}^{-}, 4-\mathrm{CH}_{3}-$, and 5- $\mathrm{CH}_{3}-\mathrm{BT}$ by conventional isotope analysis with GC/IRMS systems containing a $\mathrm{Cu} / \mathrm{Ni} / \mathrm{Pt}$ oxidation reactor; $b$ all four benzotriazoles were detected when the same mixture was analyzed using the modified standard setup containing a Ni/Ni/Pt oxidation reactor (GC/IRMS 1). GC/MS chromatograms (right) of $\mathbf{c}$ four underivatized benzotriazole species, d derivatization products of $1 \mathrm{H}-\mathrm{BT}$ methylation with
GC/MS

c)

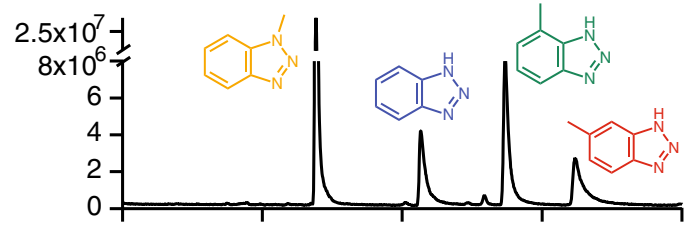

d)

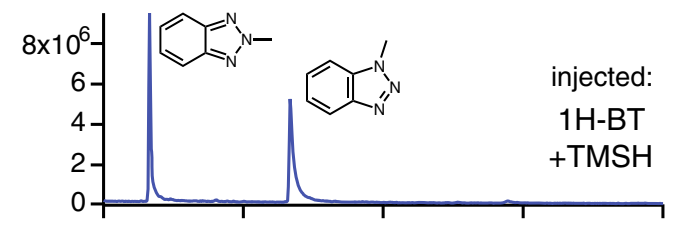

e)

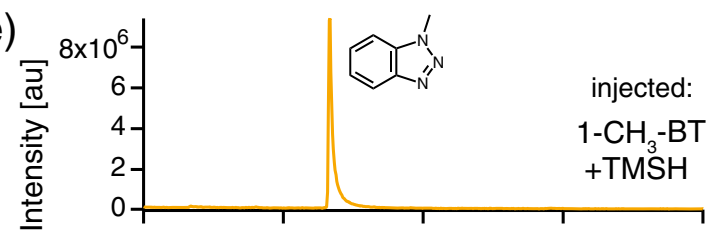

f) $1.5 \times 10^{7}-$
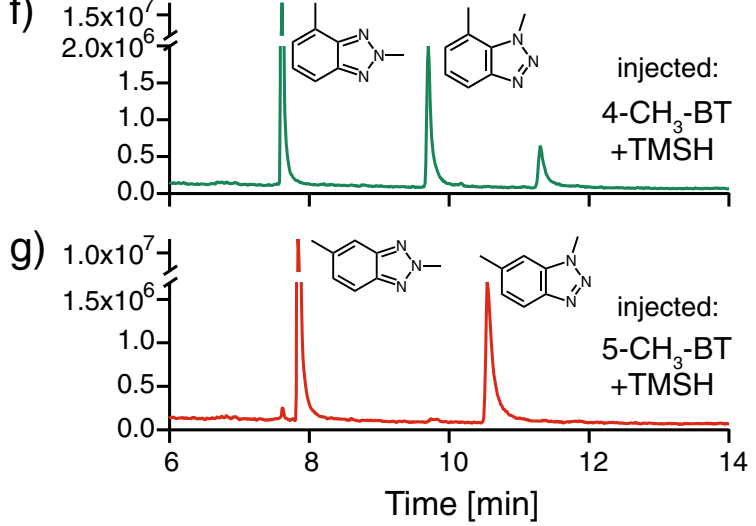

trimethylsulfonium hydroxide (TMSH) identified as $1-\mathrm{CH}_{3}-\mathrm{BT}$ and $2-\mathrm{CH}_{3}-\mathrm{BT}$ with standard compounds, e $1-\mathrm{CH}_{3}-\mathrm{BT}$, which was not further methylated upon derivatization, $\mathbf{f}$ derivatization products of 4- $\mathrm{CH}_{3}-\mathrm{BT}$ methylation, and $\mathbf{g}$ derivatization products of 5- $\mathrm{CH}_{3}-\mathrm{BT}$. Molecular structures of derivatization products for $4-\mathrm{CH}_{3}-$ and $5-\mathrm{CH}_{3}$ BT methylation are suggested based on mass spectrometric analyses without confirmation by standard compounds. Derivatization of 4$\mathrm{CH}_{3}$-BT led to a third unidentified peak of low intensity 
$\mathrm{C}$ and $\mathrm{N}$ isotope analysis of benzotriazoles using the modified standard setup

Reproducibility More than $1000 \mathrm{C}$ and $\mathrm{N}$ isotope measurements of the four benzotriazole working standards were carried out with the modified standard setup. $\mathrm{C}$ and $\mathrm{N}$ isotope signatures were highly reproducible over the whole period of analysis (Table 1, Fig. S2). Even if long-term instrumental variabilities are included, good precisions (expressed as $\pm \sigma)$ of $\pm 0.6-1.0 \%$ ( $n=79)$ for $\mathrm{C}$ and $\pm 0.1-0.3 \%$ ( $n=16-77)$ for $\mathrm{N}$ isotope analysis were achieved. Furthermore, $\delta^{13} \mathrm{C}$ and $\delta^{15} \mathrm{~N}$ values were consistent with reference isotope values determined by EA/IRMS. The trueness was within $\leq+0.5 \%$ for $\mathrm{C}$ and $\leq-0.6 \%$ for $\mathrm{N}$ isotope measurements and was thus within typical uncertainties of $\pm 0.5 \%$ and $\pm 1 \%$ reported for GC/IRMS analysis of $\mathrm{C}$ and $\mathrm{N}$ isotope ratios, respectively [27-29]. $\delta^{13} \mathrm{C}$ signatures of 1- $\mathrm{CH}_{3}-\mathrm{BT}$ showed lower precision and a reproducible offset by $-2.3 \pm 1.8 \%$ o $(n=15)$ possibly due to not fully optimized instrumental procedures at the beginning of the study. Notice the limited number of analyses owing to the depletion of our calibrated in-house standard for 1- $\mathrm{CH}_{3}-\mathrm{BT}$. Further analysis of $1-\mathrm{CH}_{3}-\mathrm{BT}$ with non-calibrated material nevertheless confirms the observed trends. $\mathrm{C}$ and $\mathrm{N}$ isotope signatures of $1-\mathrm{CH}_{3}-\mathrm{BT}$ did not deviate by more than \pm 1.5 and $\pm 0.3 \%$ from the mean of all measurements, and precisions were $\pm 0.5 \%$ o $(n=63)$ and $\pm 0.1 \%$ o $(n=58)$ for $\mathrm{C}$ and $\mathrm{N}$ isotope measurements, respectively.

Method detection limits for accurate isotope analysis The performance of $\mathrm{C}$ and $\mathrm{N}$ isotope ratio measurements using the modified standard setup was determined as a function of injected benzotriazole concentration (Figs. 2 and S3). MDLs were then derived according to the moving mean procedure as the smallest analyte concentration level, for which isotope values were within predefined intervals covering the total analytical uncertainty [26]. Measures for the total analytical uncertainty of CSIA are typically $\pm 0.5 \%$ for $\delta^{13} \mathrm{C}$ analysis of commonly measured compounds such as (chloro)hydrocarbons, but they are poorly constrained for micropollutants and especially for their $\delta^{15} \mathrm{~N}$ measurements $( \pm 1 \%)[6,28,30]$. Therefore, we also calculated MDLs using an uncertainty interval of $\pm 2 \sigma$ representing our measurement's precision.

For $\delta^{13} \mathrm{C}$ analysis of benzotriazoles, MDLs of $0.1-$ $0.3 \mathrm{mM}$ (corresponding to $0.7-1.8 \mathrm{nmol} \mathrm{C}$ ) were determined using an uncertainty interval of $\pm 0.5 \%$. Except for analysis of $1-\mathrm{CH}_{3}-\mathrm{BT}$, identical results were obtained if the

Table 1 Trueness and precision $( \pm \sigma)$ of $\mathrm{C}$ and $\mathrm{N}$ isotope measurements of four benzotriazole working standards as well as $\delta^{13} \mathrm{C}$ and $\delta^{15} \mathrm{~N}$ values of eight additional aromatic, N-heterocyclic compounds determined with the modified standard setup (GC/IRMS 1). Unless specified otherwise, isotope signatures are reported as arithmetic mean $( \pm \sigma)$ of triplicate measurements

\begin{tabular}{|c|c|c|c|c|}
\hline \multirow[b]{2}{*}{ Compound } & \multicolumn{4}{|l|}{ GC/IRMS } \\
\hline & $\delta^{13} \mathrm{C}[\% 0]$ & $\Delta \delta^{13} \mathrm{C}[\% 0]^{\mathrm{a}}$ & $\delta^{15} \mathrm{~N}[\% 0]$ & $\Delta \delta^{15} \mathrm{~N}[\%]^{\mathrm{a}}$ \\
\hline $1 \mathrm{H}-\mathrm{BT}$ & $-26.0 \pm 1.0^{\mathrm{b}}$ & $0.5 \pm 1.0^{\mathrm{b}}$ & $-27.4 \pm 0.1^{\mathrm{c}}$ & $-0.3 \pm 0.1^{\mathrm{c}}$ \\
\hline $1-\mathrm{CH}_{3}-\mathrm{BT}$ & $-33.4 \pm 1.8^{\mathrm{d}}$ & $-2.3 \pm 1.8^{\mathrm{d}}$ & $-33.5 \pm 0.1^{\mathrm{e}}$ & $-0.2 \pm 0.1^{\mathrm{e}}$ \\
\hline $4-\mathrm{CH}_{3}-\mathrm{BT}$ & $-28.8 \pm 0.6^{\mathrm{b}}$ & $0.0 \pm 0.6^{\mathrm{b}}$ & $-4.2 \pm 0.3^{\mathrm{c}}$ & $-0.6 \pm 0.3^{\mathrm{c}}$ \\
\hline $5-\mathrm{CH}_{3}-\mathrm{BT}$ & $-27.6 \pm 0.6^{\mathrm{b}}$ & $0.0 \pm 0.6^{\mathrm{b}}$ & $-15.9 \pm 0.3^{c}$ & $-0.1 \pm 0.3^{\mathrm{c}}$ \\
\hline $1-\mathrm{CH}_{3} \mathrm{OCH}_{2}-\mathrm{BT}$ & $-32.6 \pm 0.1$ & $-^{f}$ & $0.9 \pm 0.0$ & - \\
\hline Benzothiazole & $-28.9 \pm 0.1$ & - & $-2.1 \pm 0.1$ & - \\
\hline $1-\mathrm{CH}_{2} \mathrm{Cl}-\mathrm{BT}$ & $-28.5 \pm 0.0$ & - & $-5.7 \pm 0.1$ & - \\
\hline Skatole & $-25.2 \pm 0.0$ & - & $1.7 \pm 0.1$ & - \\
\hline Quinoline & $-21.8 \pm 0.1$ & - & $3.3 \pm 0.0$ & - \\
\hline Indole & $-19.5 \pm 0.1$ & - & $6.3 \pm 0.2$ & - \\
\hline $5,6-\left(\mathrm{CH}_{3}\right)_{2}-\mathrm{BT}$ & - & - & $-23.5 \pm 0.3$ & - \\
\hline 1- $\mathrm{CH}_{2} \mathrm{OH}-\mathrm{BT}$ & - & - & $-6.3 \pm 0.1$ & - \\
\hline
\end{tabular}

${ }^{a}$ Trueness is expressed as mean deviation of isotope signatures measured with GC/IRMS from the reference isotope signatures determined by EA/IRMS

${ }^{\mathrm{b}} n=79$

${ }^{c} n=77$

${ }^{\mathrm{d}} n=15$

${ }^{\mathrm{e}} n=16$

${ }^{\mathrm{f}}$ Hyphen $(-)=$ not determined 


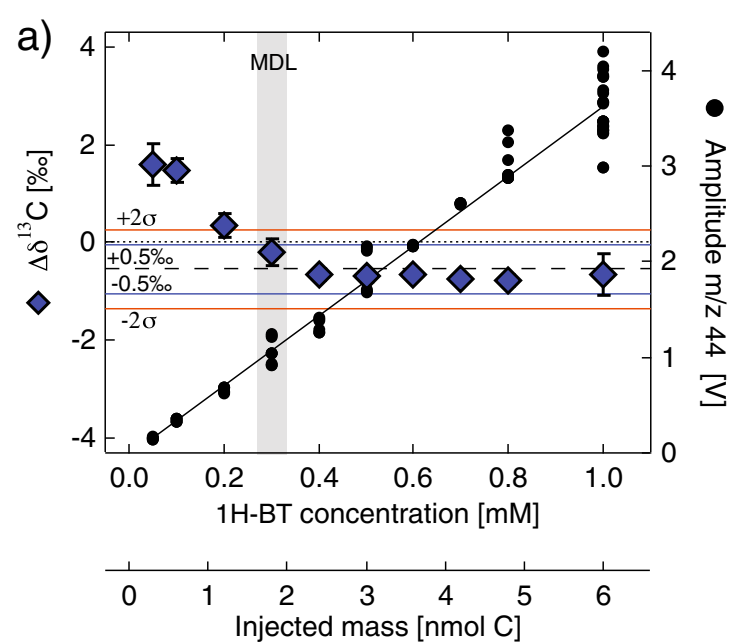

Fig. 2 Accuracies of $\mathbf{a} \mathrm{C}$ and $\mathbf{b} \mathrm{N}$ isotope signatures of 1H-BT determined with the modified standard setup (GC/IRMS 1) for a concentration range of $0.05-1 \mathrm{mM}$ and $0.25-5 \mathrm{mM}$, respectively. Amplitudes increased linearly with higher injected concentrations. Gray bars indicate MDLs determined according to the moving mean procedure [26]

MDL definition was based on the $\pm 2 \sigma$ interval (Figs. 2a and S3, Table 2). MDLs for $\delta^{15} \mathrm{~N}$ analysis of benzotriazoles were derived for uncertainty intervals of $\pm 1 \%$ and $\pm 2 \sigma$ (Fig. 2b). Due to very accurate $\mathrm{N}$ isotope measurements of benzotriazoles, MDLs of $0.125-0.25 \mathrm{mM}(0.4-0.8 \mathrm{nmol}$ $\mathrm{N})$ coincided with the lowest measured concentrations and peak amplitudes and were, again, independent of the uncertainty definition. Only for $\delta^{15} \mathrm{~N}$ measurements of $5-\mathrm{CH}_{3}$ BT, a higher $\mathrm{MDL}_{2 \sigma}$ of $1 \mathrm{mM}(3.0 \mathrm{nmol} \mathrm{N})$ was determined (Table 2).

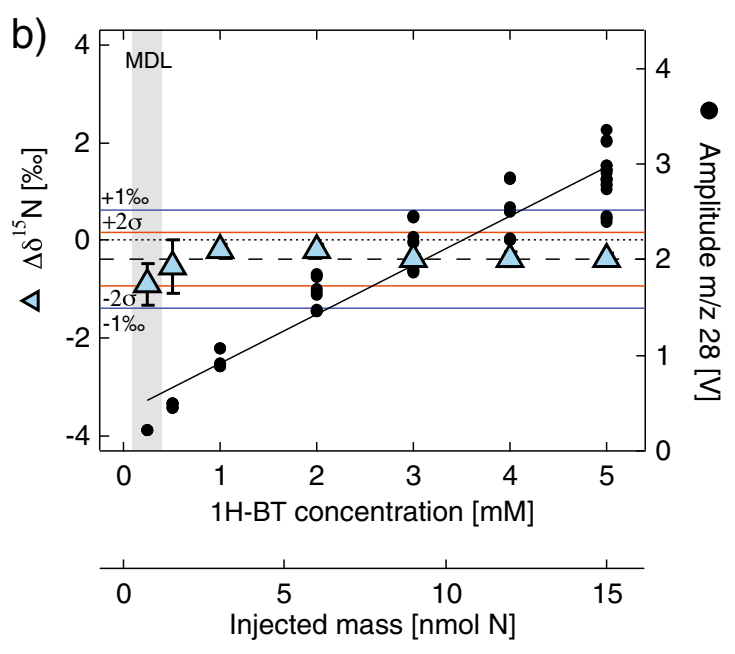

with intervals of $\pm 0.5 \%$ and $\pm 1 \%$ for $\mathrm{C}$ and $\mathrm{N}$ isotope analysis (blue lines), as well as with intervals of $\pm 2 \sigma$ (red lines). Moving means are indicated by dashed lines

Conversion efficiency The accurate and highly reproducible $\mathrm{C}$ and $\mathrm{N}$ isotope signatures as well as low MDLs suggest an efficient conversion of benzotriazoles to analyte gases $\left(\mathrm{CO}_{2}\right.$ and $\mathrm{N}_{2}$ ). To verify this hypothesis, we analyzed seven $\mathrm{C}$ and $\mathrm{N}$-containing in-house standards ( $n$-alkanes, substituted aromatic amines, nitrobenzene, atrazine) with the modified standard setup. Conversion efficiencies were operationally defined as the slope of the linear regression between signal area of mass 44 and 28, respectively, per theoretical injected mass of $\mathrm{C}$ and N.\%o Conversion efficiencies were derived

Table 2 Method detection limits (MDL) for $\mathrm{C}$ and $\mathrm{N}$ isotope analysis of benzotriazoles with the modified standard setup (GC/IRMS 1) determined according to the moving mean procedure [26] with intervals of $\pm 0.5 \%$ and $1 \%$, respectively, and $\pm 2 \sigma$. MDLs are expressed as injected benzotriazole concentration $(\mathrm{mM})$ and as corresponding mass of injected $\mathrm{C}$ and $\mathrm{N}(\mathrm{nmol})$. Corresponding peak amplitudes are reported in $\mathrm{mV}$

\begin{tabular}{|c|c|c|c|c|c|c|}
\hline & \multicolumn{3}{|l|}{$\delta^{13} \mathrm{C}$} & \multicolumn{3}{|l|}{$\delta^{15} \mathrm{~N}$} \\
\hline & \multicolumn{2}{|l|}{$\mathrm{MDL}^{\mathrm{a}}$} & \multirow{2}{*}{$\frac{\operatorname{Amp} 44^{c}}{[\mathrm{mV}]}$} & \multicolumn{2}{|l|}{$\mathrm{MDL}^{\mathrm{b}}$} & \multirow{2}{*}{$\frac{\operatorname{Amp} 28^{\mathrm{c}}}{[\mathrm{mV}]}$} \\
\hline & {$[\mathrm{mM}]$} & {$[\mathrm{nmol} \mathrm{C}]$} & & {$[\mathrm{mM}]$} & {$[\mathrm{nmol} \mathrm{N}]$} & \\
\hline $1 \mathrm{H}-\mathrm{BT}$ & 0.3 & 1.8 & $1060 \pm 130$ & 0.25 & 0.8 & $210 \pm 2$ \\
\hline 1- $\mathrm{CH}_{3}-\mathrm{BT}$ & $0.2^{\mathrm{d}} / 0.1^{\mathrm{e}}$ & $1.4 / 0.7$ & $1470 \pm 70^{\mathrm{d}} / 750 \pm 25^{\mathrm{e}}$ & 0.125 & 0.4 & $150 \pm 1$ \\
\hline 4- $\mathrm{CH}_{3}-\mathrm{BT}$ & 0.1 & 0.7 & $420 \pm 10$ & 0.25 & 0.8 & $220 \pm 2$ \\
\hline $5-\mathrm{CH}_{3}-\mathrm{BT}$ & 0.2 & 1.4 & $625 \pm 50$ & 1.0 & 3.0 & $790 \pm 115$ \\
\hline
\end{tabular}

${ }^{a}$ Determined with an interval of $\pm 0.5 \%$ or $\pm 2 \sigma=0.8,1.2,1.4$, and $1.1 \%$ for $1 \mathrm{H}-\mathrm{BT}, 1-\mathrm{CH}_{3-}$, 4- $\mathrm{CH}_{3-}$, and 5-CH${ }_{3}-\mathrm{BT}$, respectively ${ }^{b}$ Determined with an interval of $\pm 1 \% 0$ or $\pm 2 \sigma=0.5,0.6,0.6$, and $1.5 \%$ for $1 \mathrm{H}-\mathrm{BT}, 1-\mathrm{CH}_{3-}, 4-\mathrm{CH}_{3-}$, and 5- $\mathrm{CH}_{3}-\mathrm{BT}$, respectively

${ }^{\mathrm{c}}$ Amplitude $\pm \sigma$

${ }^{\mathrm{d}}$ Interval $\pm 0.5 \% 0$

${ }^{\mathrm{e}}$ Interval $\pm 2 \sigma(=1.2 \% 0)$ 
from analysis of 1.8 to $7.2 \mathrm{nmol} \mathrm{C}$ and 1.5 to $15 \mathrm{nmol} \mathrm{N}$ per substance, resulting in signal areas between 1 and $50 \mathrm{Vs}$ and amplitudes ranging from 1.2 to $10 \mathrm{~V}\left(\delta^{13} \mathrm{C}\right)$ and 0.09 to $3.4 \mathrm{~V}\left(\delta^{15} \mathrm{~N}\right)$, respectively. Figure 3 depicts the conversion efficiencies of the tested compounds to $\mathrm{CO}_{2}$ and $\mathrm{N}_{2}$, respectively, grouped by substance class.

$n$-Alkanes are reported to be the most readily combusted and most completely converted to $\mathrm{CO}_{2}$ [31]. Indeed dodecane showed the highest operational $\mathrm{CO}_{2}$-conversion efficiency ( $5.9 \mathrm{Vs} / \mathrm{nmol} \mathrm{C}$ ). Decane conversion efficiency, in contrast, only attained $82 \%$ of the dodecane value. The comparison of combustion efficiency ranges suggests that benzotriazole conversion to $\mathrm{CO}_{2}$ was also high. The four benzotriazole species showed operational conversion efficiencies between 3.7 and $5.0 \mathrm{Vs} / \mathrm{nmol} \mathrm{C}$, which corresponded to $62-85 \%$ of the dodecane conversion efficiency (Fig. 3a). All benzotriazole species were converted to a similar extent suggesting that the presence and position of a methyl substituent did not affect oxidation. Indeed, evidence for similar combustion properties of aliphatic and aromatic compounds has also been reported for $n$-hexane and toluene [32]. Moreover, the conversion of N-heterocycles seems favored over that of two aromatic amines (4-chloroaniline, diphenylamine), which only reached $35 \%$ conversion to $\mathrm{CO}_{2}$. Given that $\delta^{13} \mathrm{C}$ values of all the $\mathrm{N}$-containing compounds analyzed here can be determined accurately [30, 33-36], our data illustrate that a better conversion contributes to lower MDLs but is not prerequisite for accurate isotope analysis.

$\mathrm{N}_{2}$-conversion efficiencies additionally support the conclusion that benzotriazoles were efficiently converted to analyte gases by the $\mathrm{Ni} / \mathrm{Pt}$ reactor used in the modified standard setup. All benzotriazoles were most efficiently transformed to $\mathrm{N}_{2}$ compared to amino and nitro groups in aromatic amines and nitrobenzene (Fig. 3b). It is interesting to note that atrazine, which was successfully analyzed with a similar self-made $\mathrm{Ni} / \mathrm{NiO}$ reactor operated at $1150{ }^{\circ} \mathrm{C}$ in previous studies [34], could not be measured using the modified standard setup. We speculate that this result might be due to the lower reactor temperature used here $\left(1000^{\circ} \mathrm{C}\right)$.

Our comparison of conversion efficiency further underscores the need of standard materials and procedural guidelines for developing CSIA methods for organic micropollutants [6]. As illustrated here and shown previously [31, 37], conversion efficiencies strongly depend on the type and temperature of the oxidation reactor. In addition, standard materials are required that can be used under very different chromatographic conditions on a wide variety of IRMS instruments.

\section{Benzotriazole-CSIA using online derivatization}

We explored the C- and N-CSIA of benzotriazoles using an online derivatization approach with a conventional $\mathrm{Cu} / \mathrm{Ni} / \mathrm{Pt}$ reactor as the alternative to the modified standard setup. As shown in Fig. 1, derivatization with TMSH generates methylated benzotriazoles that do not show the same affinity to $\mathrm{Cu}$ and other metal-containing parts and thus can be analyzed in a conventional GC/IRMS system. As outlined in the methods section, derivatization requires one to reconcile isotope signatures measured for multiple methylation products (see tentative product identification in Fig. 1d, f, g)

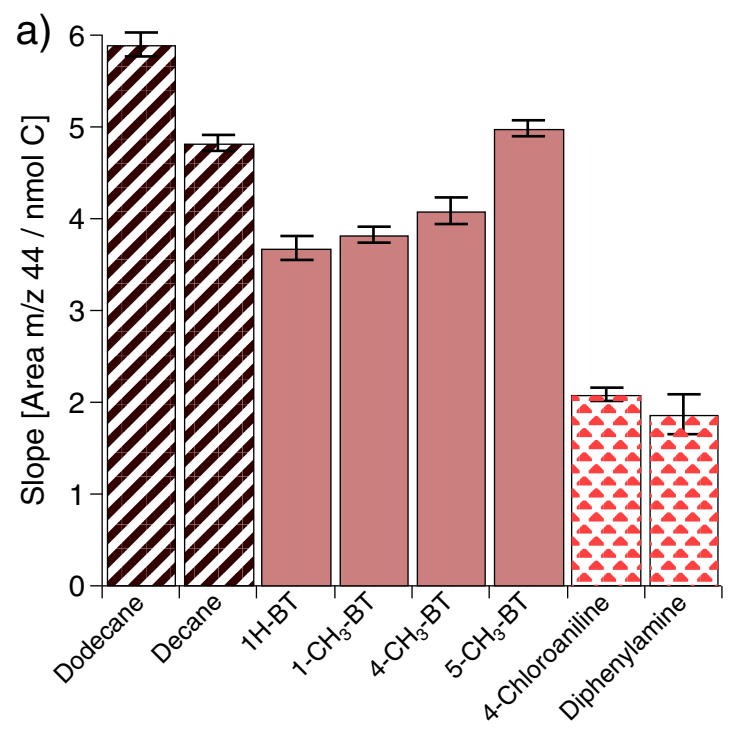

Fig. 3 Conversion of $n$-alkanes (striped bars), benzotriazoles (solid bars), substituted aromatic amines (dotted bars), nitrobenzene (squared bar), and atrazine to $\mathbf{a} \mathrm{CO}_{2}$ and $\mathbf{b} \mathrm{N}_{2}$ by the self-made

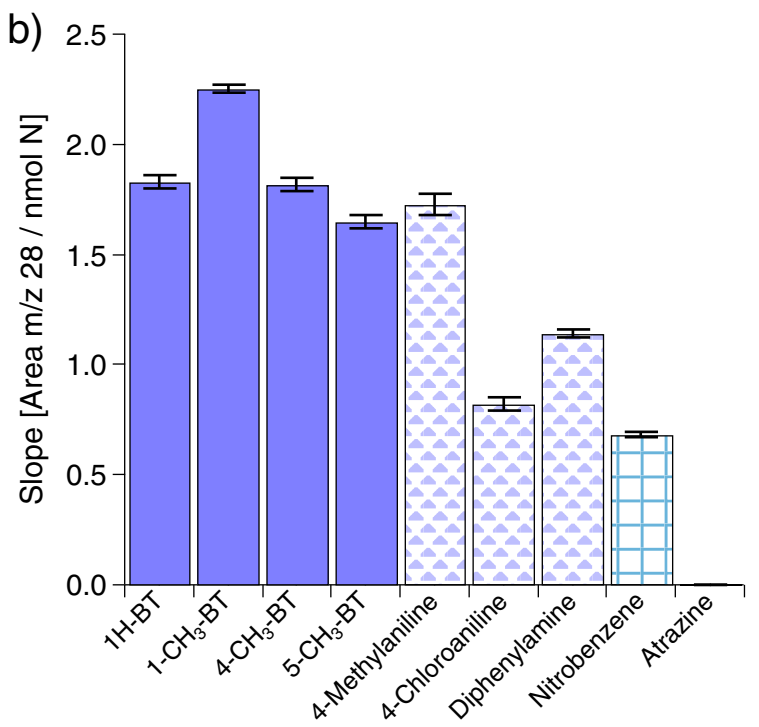

$\mathrm{Ni} / \mathrm{Ni} / \mathrm{Pt}$ reactor in the modified standard setup (GC/IRMS 1). Conversion efficiency is expressed as slope of the linear regression between theoretical injected amount of $\mathrm{C}$ or $\mathrm{N}$ and corresponding peak area 
except for 1- $\mathrm{CH}_{3}-\mathrm{BT}$, which remained unchanged (Fig. 1e). Unfortunately, GC/MS analysis revealed that benzotriazole methylation products have similar retention times than the other benzotriazoles investigated and co-elution would likely have compromised their isotopic analyses (Fig. 1d-g). Therefore, the following comparison of the derivatizationbased approach with the modified standard setup focuses exclusively on 1H-BT. To enable a direct comparison of the modified standard setup and the derivatization approach, both methods were implemented on an identical instrument (GC/IRMS 2).

Comparison of the derivatization approach with the modified standard setup Accurate and reproducible $\delta^{13} \mathrm{C}$ and $\delta^{15} \mathrm{~N}$ values were obtained with both approaches for $1 \mathrm{H}-$ BT (Fig. S4). Comparisons were made for the concentration range of $0.8-8 \mathrm{mM}$ (derivatization approach) and $1-10 \mathrm{mM}$ (modified standard setup), respectively (Fig. S5). $\delta^{13} \mathrm{C}$ values measured with the derivatization approach were of similar trueness $( \pm 0.5 \%$ of reference value) than data acquired with the modified standard setup except for concentrations below $2 \mathrm{mM}$, which, on that instrument (GC/IRMS 2), only yielded satisfactory results with the derivatization approach. Both approaches performed equally well for $\mathrm{N}$ isotope analysis for 1H-BT concentrations between 3.5 and $10 \mathrm{mM}$ but $\delta^{15} \mathrm{~N}$ values were slightly offset by $-1 \%$. Notice that in contrast to typical sample injection techniques (e.g., on column, split/splitless), the derivatization approach using the PTV injector enables one to inject variable sample sizes (1$10 \mu \mathrm{L}$ ) with constant excess of TMSH. This feature might be beneficial for benzotriazole analysis in environmental samples but was not explored further in this study. Data presented in the following sections were acquired with the modified standard setup implemented on GC/IRMS 1.

Solid-phase extraction of benzotriazoles coupled to GC/IRMS (modified standard setup)

We tested three different SPE sorbents and protocols to carry out C- and N-CSIA of benzotriazoles in different aqueous matrices, that is tap water, sewage treatment plant effluent, and activated sludge as well as in consumer products. The performance of different SPE sorbents was evaluated based on isotope fractionation, analyte recovery, and interferences from the sample matrix. Regardless of the materials and protocols chosen, no influence of the sample matrix on the analyte recovery was observed as reported earlier [38].

(1) Best results were obtained using Oasis HLB cartridges that were preconditioned with hexane, ethyl acetate, methanol and water, and with sample $\mathrm{pH}$ values adjusted to $\mathrm{pH} 2$. Using this optimized protocol (see
Table S2), benzotriazole recoveries varied between $80 \pm 4 \%$ and $93 \pm 5 \%$ (Table S3) and no co-eluting substances interfered with the analytes. Notice that the latter was not the case if Oasis HLB cartridges had not been preconditioned with hexane so that interferences from the cartridge material compromised CSIA of $1-\mathrm{CH}_{3}-\mathrm{BT}$ and $5-\mathrm{CH}_{3}-\mathrm{BT}$. Method-induced isotope fractionation, denoted as deviation $\Delta \delta^{13} \mathrm{C}$ and $\Delta \delta^{15} \mathrm{~N}$, was negligible regardless of the sample matrices used and was within the uncertainty of analysis (Table 3). Generally, $\Delta \delta^{13} \mathrm{C}$ and $\Delta \delta^{15} \mathrm{~N}$ values were slightly more negative than the reference value suggesting a preferential adsorption of heavy isotopologs. $\Delta \delta^{13} \mathrm{C}$ and $\Delta \delta^{15} \mathrm{~N}$ values of $1 \mathrm{H}-\mathrm{BT}, 4-\mathrm{CH}_{3}-\mathrm{BT}$, and 5- $\mathrm{CH}_{3}$-BT were within $-0.3 \pm 0.8$ and $-1.5 \pm 0.5 \%$. The deviation of the $\delta^{13} \mathrm{C}$ value of $1-\mathrm{CH}_{3}-\mathrm{BT}$ (up to $-2.6 \pm 1.7 \%$ ) was almost identical to the offset from the reference value measured without SPE (Table 1) suggesting that this deviation did not originate from the enrichment procedure.

(2) Using ENVI-Carb cartridges, benzotriazole recoveries were high $(80 \pm 1 \%$ to $121 \pm 11 \%$ ) (Table S3). However, co-eluting peaks impeded $\mathrm{C}$ isotope analysis of $1-\mathrm{CH}_{3}-\mathrm{BT}$ and $1 \mathrm{H}-\mathrm{BT}$ after enrichment from the sludge matrix (Fig. S1). ENVI-Carb cartridges are thus only suited for N-CSIA and C-CSIA of 4- $\mathrm{CH}_{3}-$ BT and $5-\mathrm{CH}_{3}-\mathrm{BT} . \Delta \delta^{13} \mathrm{C}$ values of $4-\mathrm{CH}_{3}-\mathrm{BT}$ and 5- $\mathrm{CH}_{3}-\mathrm{BT}$ and $\Delta \delta^{15} \mathrm{~N}$ values of all four benzotriazoles, determined after enrichment of benzotriazoles from activated sludge, showed that isotope fractionation was again negligible and within the analytical uncertainty (Table 3).

(3) SPE with Oasis MAX cartridges, which was based on anion exchange at $\mathrm{pH} 10.6$, led to only low benzotriazole recoveries between $47 \pm 10 \%$ and $90 \pm 1 \%$ in particular for $1-\mathrm{CH}_{3}$-BT due to the lack of ionic interactions with the sorbent material. This option was therefore not considered as a viable strategy for benzotriazole enrichment.

Oasis HLB cartridges were chosen for benzotriazole enrichment prior to $\mathrm{C}$ - and N-CSIA, because analyte recoveries were high and neither isotope fractionation nor co-eluting substances were observed after solid-phase extraction.

\section{Source apportionment of benzotriazoles}

Isotope signatures of benzotriazoles from different suppliers We analyzed the $\delta^{13} \mathrm{C}$ and $\delta^{15} \mathrm{~N}$ values of various commercially available benzotriazoles from six different suppliers with the modified standard setup. The corresponding values for six $1 \mathrm{H}-\mathrm{BT}$, one $4-\mathrm{CH}_{3}-\mathrm{BT}$, one $5-\mathrm{CH}_{3}-\mathrm{BT}$, 
Table $3 \delta^{13} \mathrm{C}$ and $\delta^{13} \mathrm{~N}$ values of four benzotriazole working standards determined with the modified standard setup (GC/IRMS 1) after solidphase extraction from three different aqueous matrices using Oasis HLB or ENVI-Carb cartridges

\begin{tabular}{|c|c|c|c|c|}
\hline & \multicolumn{3}{|l|}{ Oasis $\mathrm{HLB}^{\mathrm{b}}$} & \multirow{2}{*}{$\begin{array}{l}\text { ENVI-Carb }^{c} \\
\text { Sludge }\end{array}$} \\
\hline & Tap water & Effluent & Sludge & \\
\hline \multicolumn{5}{|l|}{$\Delta \delta^{13} \mathrm{C}[\% 0]^{\mathrm{a}}$} \\
\hline $1 \mathrm{H}-\mathrm{BT}$ & $-0.3 \pm 0.8$ & $-0.3 \pm 0.6$ & $-0.7 \pm 0.9$ & $-^{\mathrm{d}}$ \\
\hline $1-\mathrm{CH}_{3}-\mathrm{BT}$ & $-2.6 \pm 1.7$ & $-1.9 \pm 0.9$ & $-2.2 \pm 1.7$ & $-^{\mathrm{d}}$ \\
\hline $4-\mathrm{CH}_{3}-\mathrm{BT}$ & $-0.8 \pm 0.5$ & $-0.8 \pm 0.1$ & $-0.6 \pm 1.2$ & $1.3 \pm 0.5$ \\
\hline $5-\mathrm{CH}_{3}-\mathrm{BT}$ & $-1.4 \pm 0.5$ & $-1.3 \pm 0.3$ & $-1.5 \pm 0.5$ & $0.9 \pm 0.7$ \\
\hline \multicolumn{5}{|l|}{$\Delta \delta^{15} \mathrm{~N}\left[\%_{0}\right]^{\mathrm{a}}$} \\
\hline $1 \mathrm{H}-\mathrm{BT}$ & $-0.5 \pm 0.1$ & $-0.5 \pm 0.2$ & $-0.3 \pm 0.2$ & $0.4 \pm 0.8$ \\
\hline $1-\mathrm{CH}_{3}-\mathrm{BT}$ & $-1.1 \pm 0.6$ & $-0.4 \pm 0.2$ & $-0.4 \pm 0.1$ & $-0.6 \pm 0.4$ \\
\hline $4-\mathrm{CH}_{3}-\mathrm{BT}$ & $-0.5 \pm 0.4$ & $-0.5 \pm 0.4$ & $-1.2 \pm 0.5$ & $0.0 \pm 0.2$ \\
\hline $5-\mathrm{CH}_{3}-\mathrm{BT}$ & $-0.4 \pm 0.3$ & $-0.3 \pm 0.4$ & $-0.7 \pm 0.8$ & $-0.5 \pm 1.2$ \\
\hline
\end{tabular}

${ }^{\mathrm{a}}$ All uncertainties correspond to $\pm \sigma(n=3)$

${ }^{\mathrm{b}}$ Oasis HLB pH 2 hexane (ethyl acetate elution)

c $250 \mathrm{mg}$, MeOH elution

${ }^{\mathrm{d}}$ Co-eluting peaks from the sludge matrix impeded $\delta^{13} \mathrm{C}$ analysis

and one tolyltriazole (mixture of $4-\mathrm{CH}_{3}-$ and $5-\mathrm{CH}_{3}-\mathrm{BT}$ ) are reported in Fig. $4 \mathrm{a}, \mathrm{b}$ and Table S5. While $\delta^{13} \mathrm{C}$ of all compounds were confined to the range of $-24.8 \%$ to $-30.6 \%, \delta^{15} \mathrm{~N}$ values varied considerably more from $-4.2 \%$ to $-27.5 \%$. This observation is consistent with the reported synthetic routes of benzotriazoles, which involve multistep reactions at $\mathrm{N}$-functional groups of various $\mathrm{N}$ containing precursor materials whereas the carbon skeleton of benzene remains unchanged (see detailed discussion below). In fact, the observed $\delta^{13} \mathrm{C}$ values of $1 \mathrm{H}-, 4-\mathrm{CH}_{3}-$, and $5-\mathrm{CH}_{3}-\mathrm{BT}$ correspond to the typical carbon signatures for benzene from petrochemical sources [39]. In contrast, $\delta^{15} \mathrm{~N}$ values of $1 \mathrm{H}-\mathrm{BT}$ clustered around $-10 \%$ (Ciba and Bayer), $-15 \%$ (Ehrenstorfer), $-20 \%$ (Aldrich), and $-27 \%$ (Fluka) (Fig. 4a). Notice that uncertainties of $\delta^{15} \mathrm{~N}$ measurements were due to not fully optimized analytical procedures at the very beginning of this study and additional measurements would result in typical variations by $\pm 2 \%$. The observed variability of $\delta^{15} \mathrm{~N}$ values can arise, in principle, from different precursor materials and/or isotope fractionation during benzotriazole production [40].

Figure 5 depicts reported benzotriazole production pathways. 2-Chloronitrobenzene (compound $\mathbf{1}$ ) is reacted with ammonia to 2-nitroaniline (2), which is then reduced to the benzotriazole precursor $o$-phenylenediamine (3) [41]. A ring closing diazotization reaction of $o$-phenylenediamine with nitrous acid in dilute sulfuric acid or with sodium nitrite and acetic acid leads to the formation of 1H-BT [41, 42]. The ${ }^{15} \mathrm{~N}$ content of all $\mathrm{N}$-containing precursor substances, especially of the direct reactants $(\mathrm{o}$ phenylenediamine and $\mathrm{NO}_{2}^{-}$) contributes to the measurable
$\mathrm{N}$ isotope signature of $1 \mathrm{H}-\mathrm{BT}$. Besides, the $\delta^{15} \mathrm{~N}$ value of benzotriazole might be significantly affected by potential $\mathrm{N}$ isotope fractionation associated with bond breaking reactions during the production process or incomplete reactant conversion. No specific enrichment factors are reported for the amination reaction, $o$-phenylenediamine synthesis, and subsequent diazotization. Bulk ${ }^{15} \mathrm{~N}$ enrichment factors between $-30 \%$ and $-46 \%$ reported for the reduction of nitrobenzene to aniline [43-45], however, indicate singlereaction steps during $1 \mathrm{H}-\mathrm{BT}$ production to be strongly fractionating. The same reason is valid for $4-\mathrm{CH}_{3}-\mathrm{BT}$ and 5- $\mathrm{CH}_{3}-\mathrm{BT}$ that are produced via the same pathway as 1H-BT (Fig. 5). Indeed C isotope signatures were in the typical range of $-24.8 \%$ to $-30.6 \%$, whereas $\mathrm{N}$ isotope signatures showed higher variations (Fig. 4b).

The variations of $\delta{ }^{15} \mathrm{~N}$ values imply that an identification of benzotriazole suppliers might be possible by $\mathrm{N}-\mathrm{CSIA}$, while $\delta^{13} \mathrm{C}$ data are less indicative. A comparison of two 1H-benzotriazoles from Aldrich also suggests that there may be variabilities between different production lots through the use of different raw materials or modifications in the production process (Fig. 4a). Consequently, analysis of additional specimen from the same supplier will be necessary to confirm our interpretation.

Isotope signatures of benzotriazoles in domestic dishwashing detergents The $\delta^{13} \mathrm{C}$ and $\delta^{15} \mathrm{~N}$ values of benzotriazoles were determined in 12 domestic dishwashing tabs and powders by SPE-GC/IRMS, and their concentrations were quantified by GC/MS. Seven of the 12 dishwashing detergents analyzed contained between $0.3 \pm 0.1$ and $1.5 \pm 0.2 \mathrm{mg} / \mathrm{g}$ of 

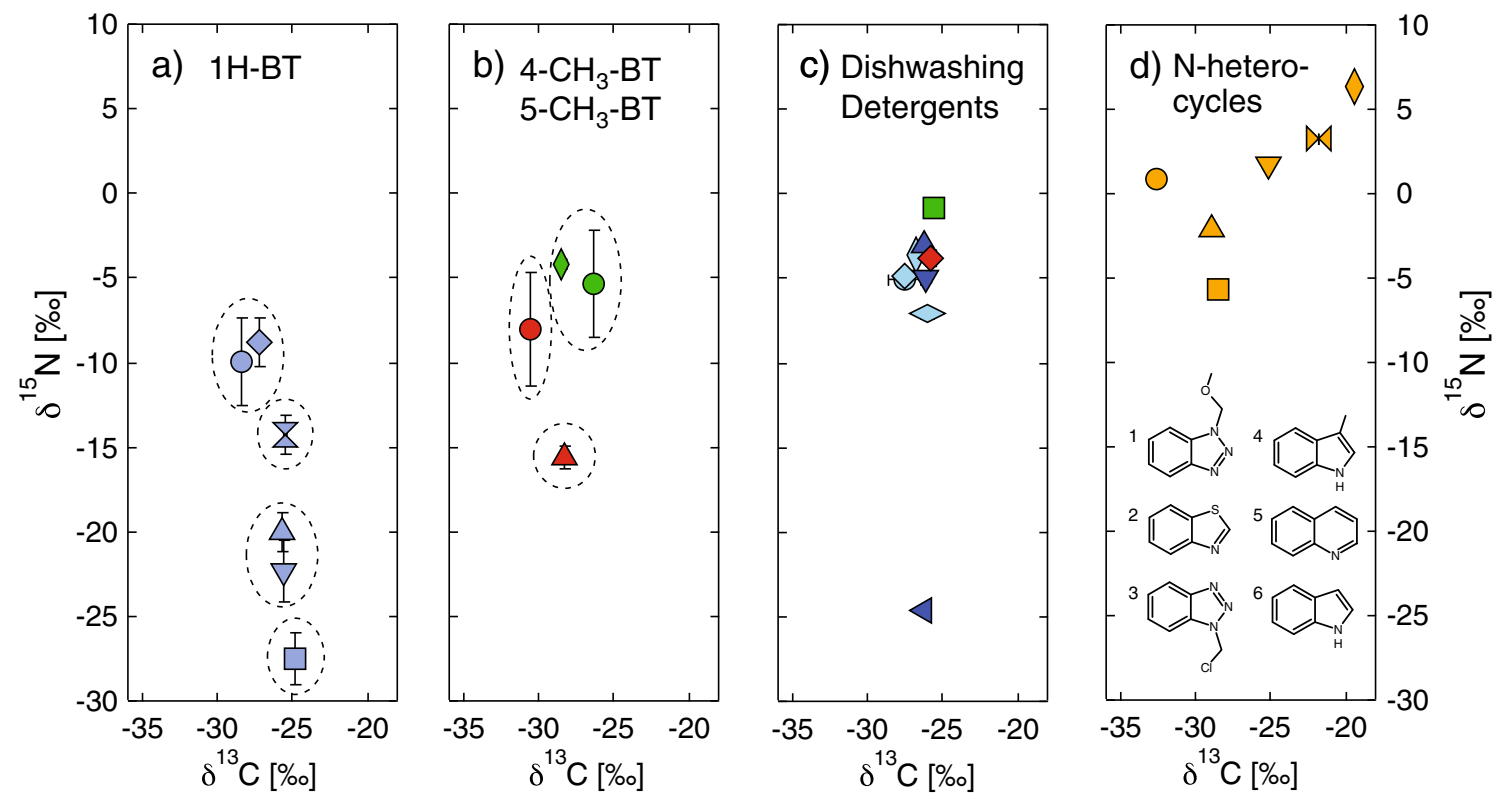

\begin{tabular}{|ll|}
\hline \multicolumn{1}{|l|}{ 1H-BT } \\
$\bigcirc$ & Ciba \\
$\diamond$ & Bayer \\
$\mathrm{Z}$ & Ehrenstorfer \\
$\triangle$ & Aldrich 016 \\
$\nabla$ & Aldrich 156 \\
$\square$ Fluka
\end{tabular}

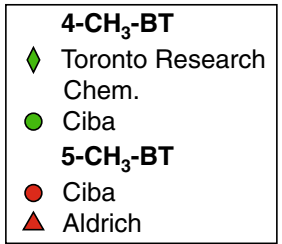

Fig. $4 \delta^{13} \mathrm{C}$ and $\delta^{15} \mathrm{~N}$ values of a $1 \mathrm{H}$-benzotriazole and $\mathbf{b} 4-\mathrm{CH}_{3}$ $\mathrm{BT}$ and $5-\mathrm{CH}_{3}-\mathrm{BT}$ from different suppliers. Clusters with similar $\mathrm{C}$ and $\mathrm{N}$ isotope ratios are indicated by dashed circles. $\delta^{13} \mathrm{C}$ and $\delta^{15} \mathrm{~N}$ values of $\mathbf{c} 1 \mathrm{H}-\mathrm{BT}, 4-\mathrm{CH}_{3}-\mathrm{BT}$, and $5-\mathrm{CH}_{3}-\mathrm{BT}$ in domestic dishwashing detergents from different retailers (A-F) and $\mathbf{d}$ further

1H-BT, while 4- $\mathrm{CH}_{3}-\mathrm{BT}$ and 5- $\mathrm{CH}_{3}-\mathrm{BT}$ were detected in only one dishwashing tab $(0.8 \pm 0.2 \mathrm{mg} / \mathrm{g}$, see Table S6). Four specimens did not contain measurable concentrations of benzotriazoles $(<0.01 \mathrm{mg} / \mathrm{g}$ from $100 \mathrm{mg}$ of detergent).

\begin{tabular}{|c|c|}
\hline 1H-BT & \\
\hline Supplier A & Others \\
\hline$\triangle A 1$ & $\diamond \mathrm{B}$ \\
\hline$\nabla \mathrm{A} 2$ & $O C$ \\
\hline$\triangle A 3$ & $\begin{array}{l}\diamond \mathrm{D} \\
\diamond \mathrm{E}\end{array}$ \\
\hline 4-CH $-\mathrm{CH}_{3}-\mathrm{BT}$ & $\square F$ \\
\hline $5-\mathrm{CH}_{3}-\mathrm{BT}$ & $\diamond F$ \\
\hline
\end{tabular}

aromatic, N-heterocyclic compounds (numbers 1-6 indicate structural formulas). All measurements were conducted with the modified standard setup (GC/IRMS 1). Standard deviations of triplicate $C$ isotope measurements are usually $<0.5 \%$ and smaller than marker size

$\delta^{13} \mathrm{C}$ of the detected benzotriazole species was confined to values between -25.6 and $-27.5 \%$ (Fig. $4 \mathrm{c}$ ), that is in the typical range for $\delta^{13} \mathrm{C}$ values reported for different benzotriazole suppliers (Fig. 4a, b). Six out of seven 1H-BT-
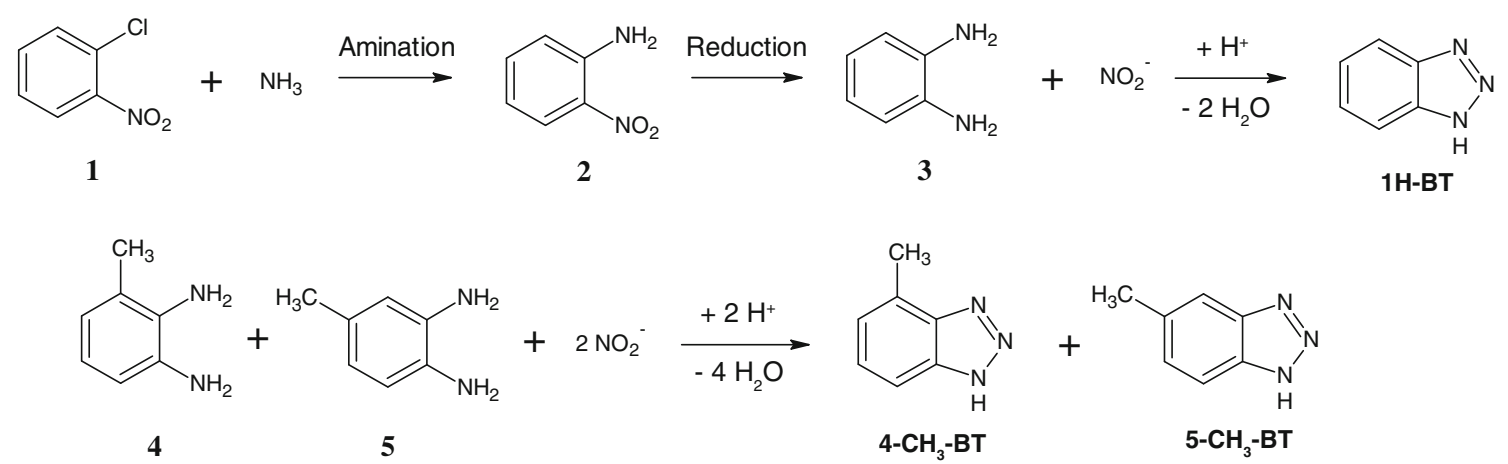

Fig. 5 Synthetic routes to benzotriazole by reaction of $o$ phenylenediamine (3) with nitrous acid in dilute sulfuric acid or acetic acid [41, 42]. Synthesis of $o$-phenylenediamine is reported from reduction of 2-nitroaniline (2), which is produced by amination of 2-chloronitrobenzene (1) [41]. Lower panel: Synthesis of tolyltriazole (4- $\mathrm{CH}_{3}-$ and $5-\mathrm{CH}_{3}-\mathrm{BT}$ ) by reaction of $o$-toluylenediamine (a mixture of 2,3-diaminotoluene (4) and 3,4-diaminotoluene (5)) with nitrite in acidic solution [46] 
containing dishwashing detergents exhibited similar $\delta^{15} \mathrm{~N}$ values between $-3.0 \%$ and $-7.1 \%$. Only one tab (A3) had a distinctly different $\mathrm{N}$ isotope signature of $-24.6 \%$.

Even though this sampling campaign was not based on a representative selection of dishwashing detergent manufacturers and retailers, a tentative source apportionment of benzotriazole supplies can be made from CSIA data. The $\delta^{15} \mathrm{~N}$ data obtained for different dishwashing detergents cluster around $-5 \pm 2 \%$ suggesting a common origin. Based on the $\delta^{15} \mathrm{~N}$ of $1 \mathrm{H}-\mathrm{BT}$ in dishwashing detergents, their $1 \mathrm{H}$-BT seems closely related to that produced by Ciba $(-9.9 \%)$ and Bayer $(-8.8 \%)$, while the $\delta^{15} \mathrm{~N}$ of one dishwashing tab (A3) agrees with data for $1 \mathrm{H}-\mathrm{BT}$ from Aldrich and Fluka (Fig. 4a, c). The $\delta^{13} \mathrm{C}$ and $\delta^{15} \mathrm{~N}$ values of tolyltriazole in dishwashing detergent $\mathrm{F}$ can also be tentatively related to $4-\mathrm{CH}_{3}-\mathrm{BT}$ and $5-\mathrm{CH}_{3}-\mathrm{BT}$ from Ciba (Fig. $4 \mathrm{~b}$, c). We detected slightly more positive $\delta^{15} \mathrm{~N}$ of benzotriazoles in dishwashing detergents compared to the pure chemicals. Based on our limited data set, it is currently unclear whether these differences arise from isotope fractionation during dishwashing detergent production or are an indication of benzotriazoles produced by other suppliers.

Isotope analysis of further aromatic, heterocyclic compounds The applicability of our instrumental approach for the CSIA of benzotriazoles was tested with the analysis of additional, substituted aromatic $\mathrm{N}$-heterocycles of similar molecular structures. Isotope signatures of chloromethyland methoxymethyl-benzotriazole as well as benzothiazole, indole, skatole, and quinoline are shown in Fig. 4d and corresponding isotope values are listed in Table 1. 2Aminobenzimidazole could not be analyzed while measurements of 1-hydroxymethyl- and 5,6-dimethyl-benzotriazole were successful for $\mathrm{N}$ isotopes only. In contrast to benzotriazoles, $\delta^{13} \mathrm{C}$ values of six aromatic $\mathrm{N}$-heterocycles spanned over a larger range $(-19.5 \pm 0.1$ to $-32.6 \pm 0.1 \% 0)$ suggesting that in addition to benzene, alternative $\mathrm{C}$-based precursor materials may have been used in synthesis. $\delta^{15} \mathrm{~N}$ values partly matched the values of benzotriazoles from dishwashing detergents $(+6.3 \pm 0.2$ and $-5.7 \pm 0.1 \%$, Fig. $4 d)$ but were generally more enriched in ${ }^{15} \mathrm{~N}$ than the pure benzotriazoles (Fig. 4a). Note, however, that the range of chemicals investigated was rather limited and a more comprehensive study is needed to establish isotopic fingerprinting of these chemicals.

\section{Environmental significance}

Our study shows that the applicability of CSIA can be expanded towards more polar organic micropollutants through modifications of standard approaches to GC/IRMS. Because of the excellent long-term performance and good precision of Ni-based combustion reactors, this approach is likely to work equally well with other polar organic compounds such as nitro- and aminoaromatic compounds, whose isotopic composition is presently analyzed by conventional means $[30,47]$.

The coupling of solid-phase extraction to the modified standard setup used here for the source apportionment of benzotriazoles in dishwashing detergents is an important first step towards analyzing this emerging class of micropollutants in aquatic systems. Given the limited knowledge of benzotriazole (bio)degradation pathways, our work provides the foundations for accurate measurements of isotope fractionation trends in laboratory experiments, which will enable the identification of transformation mechanisms [4, 7]. In addition, this study offers new avenues for further method development for benzotriazole-CSIA in environmental samples. Typical 1H-benzotriazole concentrations in groundwater, rivers, and sewage treatment plant effluents $(0.2-2 \mu \mathrm{g} / \mathrm{L}[14,48-50])$, however, illustrate that substantial preconcentration of up to $10^{5}$-fold will be necessary to reach MDLs proposed here. Optimizing SPE procedures for a selective benzotriazole enrichment from environmental samples is one of the major challenges of CSIA.

Acknowledgements We acknowledge the financial support from the Swiss Federal Office for the Environment and the German Federal Environmental Foundation (DBU).

\section{References}

1. Schwarzenbach RP, Escher BI, Fenner K, Hofstetter TB, Johnson CA, von Gunten U, Wehrli B (2006) The challenge of micropollutants in aquatic systems. Science 313:1072-1077

2. Schwarzenbach RP, Egli T, Hofstetter TB, von Gunten U, Wehrli B (2010) Global water pollution and human health. Annu Rev Environ Resour 35:109-136

3. Hofstetter T, Berg M (2011) Assessing transformation processes of organic contaminants by compound-specific stable isotope analysis. TrAC-Trends Anal Chem 30:618-627

4. Elsner M (2010) Stable isotope fractionation to investigate natural transformation mechanisms of organic contaminants: principles, prospects and limitations. J Environ Monit 12:2005-2031

5. Schmidt TC, Zwank L, Elsner M, Berg M, Meckenstock RU, Haderlein SB (2004) Compound-specific stable isotope analysis of organic contaminants in natural environments: a critical review of the state of the art, prospects, and future challenges. Anal Bioanal Chem 378:283-300

6. Elsner M, Jochmann MA, Hofstetter TB, Hunkeler D, Bernstein A, Schmidt TC, Schmimmelmann A (2012) Current challenges in compound-specific stable isotope analysis of environmental organic contaminants. Anal Bioanal Chem 403:2471-2491

7. Hofstetter TB, Schwarzenbach RP, Bernasconi SM (2008) Assessing transformation processes of organic compounds using stable isotope fractionation. Environ Sci Technol 42:7737-7743 
8. Blessing M, Jochmann MA, Schmidt TC (2008) Pitfalls in compound-specific isotope analysis of environmental samples. Anal Bioanal Chem 390:591-603

9. Reinnicke S, Juchelka D, Steinbeiss S, Meyer A, Hilkert A, Elsner M (2012) Gas chromatography-isotope ratio mass spectrometry of recalcitrant target compounds: performance of different combustion reactors and strategies for standardization. Rapid Commun Mass Spectrom 26:1053-1060

10. Bi E, Schmidt TC, Haderlein SB (2006) Sorption of heterocyclic organic compounds to reference soils: column studies for process identification. Environ Sci Technol 40:5962-5970

11. Bi E, Schmidt TC, Haderlein SB (2007) Environmental factors influencing sorption of heterocyclic aromatic compounds to soil. Environ Sci Technol 41:3172-3178

12. Bi E, Zhang L, Schmidt TC, Haderlein SB (2009) Simulation of nonlinear sorption of $\mathrm{N}$-heterocyclic organic contaminates in soil columns. J Contam Hydrol 107:58-65

13. Voutsa D, Hartmann P, Schaffner C, Giger W (2006) Benzotriazoles, alkylphenols and bisphenol A in municipal wastewaters and in the Glatt River, Switzerland. Environ Sci Pollut Res 13:333341

14. Giger W, Schaffner C, Kohler H-PE (2006) Benzotriazole and tolyltriazole as aquatic contaminants. 1. Input and occurrence in rivers and lakes. Environ Sci Technol 40:71867192

15. Reemtsma T, Miehe U, Duennbier U, Jekel M (2010) Polar pollutants in municipal wastewater and the water cycle: occurrence and removal of benzotriazoles. Water Res 44:596-604

16. Weiss S, Jakobs J, Reemtsma T (2006) Discharge of three benzotriazole corrosion inhibitors with municipal wastewater and improvements by membrane bioreactor treatment and ozonation. Environ Sci Technol 40:7193-7199

17. Cornell JS, Pillard DA, Hernandez MT (2000) Comparative measures of the toxicity of component chemicals in aircraft deicing fluid. Environ Toxicol Chem 19:1465-1472

18. Kiss A, Fries E (2009) Occurrence of benzotriazoles in the rivers Main, Hengstbach, and Hegbach (Germany). Environ Sci Pollut Res 16:702-710

19. Katritzky AR, Lan X, Yang JZ, Denisko OV (1998) Properties and sythetic utility of $\mathrm{N}$-substituted benzotriazoles. Chem Rev 98:409-548

20. Hart DS, Davis LC, Erickson LE, Callender TM (2004) Sorption and partitioning parameters of benzotriazole compounds. Microchem J 77:9-17

21. Liu Y-S, Ying G-G, Shareef A, Kookana RS (2011) Biodegradation of three selected benzotriazoles under aerobic and anaerobic conditions. Water Res 45:5005-5014

22. Mawhinney DB, Vanderford BJ, Snyder SA (2012) Transformation of $1 \mathrm{H}$-benzotriazole by ozone in aqueous solution. Environ Sci Technol 46:7102-7111

23. Allam NK, Nazeer AA, Ashour EA (2009) A review of the effects of benzotriazole on the corrosion of copper and copper alloys in clean and polluted environments. J Appl Electrochem 39:961969

24. Finsgar M, Milosev I (2010) Inhibition of copper corrosion by 1,2,3-benzotriazole: a review. Corros Sci 52:2737-2749

25. Reinnicke S, Bernstein A, Elsner M (2010) Small and reproducible isotope effects during methylation with trimethylsulfonium hydroxide (TMSH): a convenient derivatization method for isotope analysis of negatively charged molecules. Anal Chem 82:2013-2019

26. Jochmann MA, Blessing M, Haderlein SB, Schmidt TC (2006) A new approach to determine method detection limits for compound- specific isotope analysis of volatile organic compounds. Rapid Commun Mass Spectrom 20:3639-3648

27. Hunkeler D, Bernasconi SM (2010). In: Aelion CM, Höhener $\mathrm{P}$, Hunkeler D, Aravena R (eds) Environmental isotopes in biodegradation and bioremediation. CRC Press, Boca Raton, pp 23-42

28. Sherwood Lollar B, Hirschorn SK, Chartrand MMG, LacrampeCouloume G (2007) An approach for assessing total instrumental uncertainty in compound-specific carbon isotope analysis: implications for environmental remediation studies. Anal Chem 79:3469-3475

29. Sessions AL (2006) Isotope-ratio detection for gas chromatography. J Sep Sci 29:1946-1961

30. Skarpeli-Liati M, Turgeon A, Garr AN, Arnold WA, Cramer CJ, Hofstetter TB (2011) pH-dependent equilibrium isotope fractionation associated with the compound specific nitrogen and carbon isotope analysis of substituted anilines by SPME-GC/IRMS. Anal Chem 83:1641-1648

31. Merritt DA, Freeman KH, Ricci MP, Studley SA, Hayes JM (1995) Performance and optimization of a combustion interface for isotope ratio monitoring gas chromatography/mass spectrometry. Anal Chem 67:2461-2473

32. Schmitt J, Glaser B, Zech W (2003) Amount-dependent isotopic fractionation during compound-specific isotope analysis. Rapid Commun Mass Spectrom 17:970-977

33. Skarpeli-Liati M, Pati SG, Bolotin J, Eustis SN, Hofstetter TB (2012) Carbon, hydrogen, and nitrogen isotope fractionation associated with oxidative transformation of substituted $N$-alkyl amines. Environ Sci Technol 46:7189-7198

34. Meyer AH, Penning H, Lowag H, Elsner M (2008) Precise and accurate compound specific carbon and nitrogen isotope analysis of atrazine: critical role of combustion oven conditions. Environ Sci Technol 42:7757-7763

35. Hofstetter TB, Spain JC, Nishino SF, Bolotin J, Schwarzenbach RP (2008) Identifying competing aerobic nitrobenzene biodegradation pathways using compound-specific isotope analysis. Environ Sci Technol 42:4764-4770

36. Pati SG, Shin K, Skarpeli-Liati M, Bolotin J, Eustis SN, Spain JC, Hofstetter TB (2012) Carbon and nitrogen isotope effects associated with the dioxygenation of aniline and diphenylamine. Environ Sci Technol 46:11844-11853

37. Merritt DA, Hayes JM (1994) Nitrogen isotopic analyses by isotope-ratio-monitoring gas chromatography/mass spectrometry. J Am Soc Mass Spectrom 5:387-397

38. Weiss S, Reemtsma T (2005) Determination of benzotriazole corrosion inhibitors from aqueous environmental samples by liquid chromatography-electrospray ionization-tandem mass spectrometry. Anal Chem 77:7415-7420

39. Smallwood BJ, Philp RP, Allen JD (2002) Stable carbon isotopic composition of gasolines determined by isotope ratio monitoring gas chromatography mass spectrometry. Org Geochem 33:149-159

40. Philp RP (2007) The emergence of stable isotopes in environmental and forensic geochemistry studies: a review. Environ Chem Lett 5:57-66

41. Smiley RA (2002) Ullmann's encyclopedia of industrial chemistry. Wiley-VCH Verlag GmbH \& Co. KGaA, Weinheim

42. Chan MS, Hunter WE (1981) United States Patent 4,299,965. Preparation of benzotriazole. pat. 4,299,965

43. Gorski CA, Nurmi JT, Tratnyek PG, Hofstetter TB, Scherer MM (2010) Redox behavior of magnetite: implications for contaminant reduction. Environ Sci Technol 44:55-60

44. Hartenbach AE, Hofstetter TB, Aeschbacher M, Sander M, Kim D, Strathmann TJ, Arnold WA, Cramer CJ, Schwarzenbach RP 
(2008) Variability of nitrogen isotope fractionation during the reduction of nitroaromatic compounds with dissolved reductants. Environ Sci Technol 42:8352-8359

45. Hartenbach AE, Hofstetter TB, Berg M, Bolotin J, Schwarzenbach RP (2006) Using nitrogen isotope fractionation to assess abiotic reduction of nitroaromatic compounds. Environ Sci Technol 40:7710-7716

46. Schnegg U, Bormann U (1990) United States Patent 4,918,195. Process for preparing triazoles fused with aromatic systems by reaction of $o$-arylenediamines with nitrites. pat., 4,918,195

47. Berg M, Bolotin J, Hofstetter TB (2007) Compound-specific nitrogen and carbon isotope analysis of nitroaromatic compounds in aqueous samples using solid-phase microextraction coupled to GC/IRMS. Anal Chem 79:2386-2393
48. Janna H, Scrimshaw MD, Williams RJ, Churchley J, Sumpter JP (2011) From dishwasher to tap? Xenobiotic substances benzotriazole and tolytriazole in the environments. Environ Sci Technol 45:3858-3864

49. Wolschke H, Xie Z, Möller A, Sturm R, Ebinghaus R (2011) Occurrence, distribution and fluxes of benzotriazoles along the German large river basins into the North Sea. Water Res 45:62596266

50. Huntscha S, Singer HP, McArdell CS, Frank CE, Hollender J (2012) Multiresidue analysis of 88 polar organic micropollutants in ground, surface and wastewater using online mixed-bed multilayer solid-phase extraction coupled to high performance liquid chromatography-tandem mass spectrometry. J Chromatogr A 1268:74-83 